ЗВАРИЧ В. Н.

\title{
ОСОБЕННОСТИ НАХОЖДЕНИЯ ХАРАКТЕРИСТИЧЕСКОЙ ФУНКЦИИ ПОРОЖДАЮЩЕГО ПРОЦЕССА В МОДЕЛИ СТАЦИОНАРНОГО ЛИНЕЙНОГО AR(2) ПРОЦЕССА С ОТРИЦАТЕЛЬНЫМ БИНОМИАЛЬНЫМ РАСПРЕДЕЛЕНИЕМ
}

\author{
Институт электродинамики Национальной академии наук Украины, \\ Украина, Киев, 03057, пр-т Победьл, 56
}

\begin{abstract}
Аннотация. Рассмотрен линейный случайный процесс авторегрессии $\mathrm{AR}(2)$ имеющий отрицательное биномиальное распределение $\xi_{t}+a_{1} \xi_{t-1}+a_{2} \xi_{t-2}=\varsigma_{t}, t \in Z$, где $\left\{a_{1}, a_{2} \neq 0\right\}$ параметры авторегрессии, $Z=\{\ldots,-1,0,1, \ldots\}$ последовательность целых чисел, $\left\{\zeta_{t}, t \in Z\right\}$ случайный процесс с дискретным временем и независимыми значениями, имеющий безгранично-делимый закон распределения, который называют порождающим. Представлен метод нахождения характеристической функции порождающего процесса для линейного процесса авторегрессии, имеющего отрицательное биномиальное распределение. Для решения этой обратной задачи использованы свойства характеристической функции стационарного линейного случайного процесса авторегрессии, которая представляется в канонической форме Колмогорова и как линейный стационарный процесс авторегрессии. Представлен пример нахождения пуассоновского спектра скачков и характеристической функции для линейного процесса авторегрессии второго порядка, имеющего отрицательное биномиальное распределение.
\end{abstract}

Ключевые слова: линейный случайный процесс авторегрессии; характеристическая функция; безгранично-делимые распределения; отрицательное биномиальное распределение

В статистической радиотехнике, радиолокации, телеметрии, гидроакустике метеорологии, биомедицинских исследованиях возникает задача определения статистических характеристик воздействующего на линейную систему стохастического сигнала, описываемого случайным процессом, в случае, когда известны характеристики линейной системы и статистические характеристики отклика на такое воздействие [1-5]. При гауссовом воздействии решение такой задачи не вызывает затруднений. Однако, если отклик не имеет гауссового распределения, задача нахождения воздействующего на линейную систему сигнала с учетом характеристик его распределения достаточно сложна $[1-3,6,7]$.
Развитие и широкое использование средств вычислительной техники в системах анализа информационных сигналов предполагают применение моделей с дискретным временем и дискретными распределениями. К таким случайным процессам с дискретным временем, которые возможно использовать в качестве математических моделей информационных сигналов, относятся процессы авторегрессии [5, 8-11].

Процессы авторегрессии получили широкое применение в задачах распознавания случайных сигналов [4], моделирования [5, 7, 9, 12], и синтеза таких сигналов [13]. В приложениях такие процессы используются при решении задач распознавании речи, построении систем мобильной связи, биомедицинских ис- 
Проценко // Радиоэлектроника. - 1982. — Т. 25, № 9. - С. 31-37. - (Известия вузов).

4. Зварич B. Н. Метод нахождения характеристических функций порождающих процессов для линейных процессов авторегрессии / В.Н.Зварич, Б. Г. Марченко // Радиоэлектроника. - 1999. - Т. 42, № 8. - С. 64-71. - (Известия вузов).

5. Зварич В. Н. Линейные случайные процессы в некоторых задачах моделирования информационных сигналов / В. Н. Зварич, Б. Г. Марченко, Н. С. Бедный // Электронное моделирование. - 2001. - Т. 23, № 3. - C. 79-88.

6. Болдин М. В. Оценка распределения возмущений в схеме авторегрессии / М. В. Болдин // Теория вероятностей и ее приложения. — 1982. — Т. 27, № 4. C. 805-810. - Режим доступа : http://mi.mathnet.ru/tvp2439.

7. Al-Smadi A. Fitting ARMA models to linear non-Gaussian processes using higher order statistics / Adnan Al-Smadi, Ahmad Alshamali // Signal Processing. - Nov. 2002. - Vol. 82, No. 11. - P. 1789-1793. DOI : 10.1016/S0165-1684(02)00340-7.

8. Андерсон T. Статистический анализ временных рядов / Т. Андерсон : пер. с англ. — М. : Мир, 1976. $755 \mathrm{c}$.

9. Бокс Дж. Анализ временных рядов. Прогноз и управление : в 2 т. Т. 1 / Дж. Бокс, Г. Дженкинс : пер. с англ. — М. : Мир, 1974. - 172 с.

10. Марпл-мл. С. Л. Цифровой спектральный анализ и его приложения / С. Л. Марпл-мл. : пер. с англ. - М. : Мир, 1990. - 584 с.

11. Зварич B. Н. Характеристическая функция порождающего процесса в модели стационарного процесса авторегрессии // В. Н. Зварич, Б. Г. Марченко // Радиоэлектроника. - 2002. - Т. 45, № 8. - С. 12-18. - (Известия вузов).

12. Diversi R. Fast filtering of noisy autoregressive signals / Roberto Diversi, Roberto Guidorsi // Signal Processing. - Nov. 2007. - Vol. 87, No. 11. - P. 2843-2849. — DOI : 10.1016/j.sigpro.2007.05.018.

13. Комелев В. И. Синтез АРСС-моделей эхо сигналов / В. И. Кошелев, В. Г. Андреев // Радиоэлектроника. - 1997. - Т. 40, № 7. - С. 8-13. - (Известия вузов).

14. Красильников А. И. Нахождение пуассоновского спектра скачков отклика линейной системы при воздействии белого шума / А. И. Красильников // Пространственно-временная обработка сигналов и учет влияния среды их распостранения : сб. научн. трудов. - Харьков : ХАИ, 1980. - С. 38-40.

15. Krasilnikov A. I. A mathematical model of linear random processes in substantiation of diagnostic criteria in vibratiry diagnistics of rolling-contact bearing / A. I. Krasilnikov, B. G. Marchenko, M. V. Myslovich. Vibration Engineering. Hemisphere Pub. Corp., 1989. Vol. 3. - P. 205-211.

16. Красильников А. И. Модели шумовых сигналов в системах диагностики теплоэнергетического 
оборудования / А. И. Красильников. - К. : Полиграф-сервис, 2014. - $112 \mathrm{c}$.

17. Cox D. R. Statistical analysis of time series: Some recent developments / D. R. Cox // Scand. J. Statist. 1981. - Vol. 8, No. 2. - P. 93-115. - URL : http://www.jstor.org/stable/4615819.

18. Lawrance A. J. The innovation distribution of gamma distributed autoregressive process / A. J. Lawrance // Scand. J. Statist. - 1982. - Vol. 9, No. 4. - P. 234-236. - URL : http://www.jstor.org/stable/4615888.

19. McKenzie Ed. Innovation distributions for gamma and negative binomial autoregressions / Ed. McKenzie // Scand. J. Statist. — 1987. - Vol. 14, No. 1. - P. 79-85. - URL : http://www.jstor.org/stable/4616050.

20. Kreiss J.-P. Estimation of the distribution function of noise in stationary processes / J.-P. Kreiss // Metrika. - Dec. 1991. — Vol. 38, No. 1. - P. 285-297. —DOI : $\underline{10.1007 / \mathrm{BF} 02613623}$.
21. Биллингсли П. Сходимость вероятностных мер / П. Биллингсли : пер. с англ. — М. : Наука, 1977. $-352 \mathrm{c}$.

22. Хэннан Э. Многомерные временные ряды / Э. Хеннан : пер. с англ. - М. : Мир, 1974. - 575 с.

23. Niemi $H$. On the effects of a nonstationary noise on ARMA models / Hannu Niemi // Scand. J. Statist. 1983. - Vol. 10, No. 1. - P. 11-17. - URL : http://www.jstor.org/stable/4615895.

24. Марченко Б. Г. Метод статистических интегральных представлен и его приложения в радиотехнике / Б. Г. Марченко. - К. : Накова думка, 1973. $191 \mathrm{c}$.

25. Маляренко А. П. Пуасонівські спектри стрибків лінійних випадкових процесів / А. П. Маляренко, Б. Г. Марченко // Вісник ТНТУ. — 1997. - Т. 2, № 2. - C. 12-17.

26. Лукач E. Характеристические функции / Е. Лукач : пер. с англ. - М. : Наука, 1979. — 432 с. 